\title{
EFFECT OF ZINC SUPPLEMENT ON GLYCEMIC CONTROL AND LIPID ABNORMALITIES IN TYPE 2 DIABETIC PATIENTS.
}

1. MBBS, FCPS (Medicine)

Associate Consultant \& Associate

Professor Internal Medicine

King Abdullah Bin Abdulaziz University Hospital,

Princess Noura Bint Abdurrahman University, Riyadh, KSA.

2. MBBS, MD (Medicine)

Associate Professor Medicine KIMS, Malir Cantt, Karachi.

3. BS, FCPS (Medicine) Professor \& Head Medicine KIMS Malir Cantt Karachi.

4. MBBS, FCPS (Skin), D-DERM (UK Associate Professor \& Head Dermatology KIMS, Malir Cantt Karachi.

5. MBBS

Resident Surgery AKU, Karachi.

6. MBBS, FCPS (Psychiatry) Assistant Professor Psychiatry DUHS, OJHA Campus.

Correspondence Address:

Dr. Furquana Niaz

Department of Dermatology

House No. B 196/15 Gulistane Jouhar

Karachi.

furquananiaz@hotmail.com

Article received on:

16/08/2019

Accepted for publication

25/01/2020

\section{INTRODUCTION}

Diabetes mellitus (DM) (Type 2) is an important health issue worldwide as it increased the morbidity and mortality. The worldwide prevalence of DM is $8.5 \%$ and it is expected that 300 million people will be affected by DM by the year 2030 . The overall prevalence of type 2 DM in Pakistan is $10 \% .{ }^{2}$ There are so many factors, which affect the glycemic control in diabetic patients. One study demonstrated that male gender, increasing age and longer duration of DM were associated with poor glycemic control. ${ }^{3}$

Trace elements are important for human body as they play their role in body structure and work as co factor for many enzymes to control the metabolism. They also reduce oxidative stresses. The alteration of trace element increases oxidative stress in human bodies which may lead to complications in diabetic patients. Previous literature demonstrated that trace element deficiency was associated with DM. it was reported that trace elements have role in decreasing blood sugar by increasing insulin secretion and reducing its resistance. These trace elements are chromium, magnese, molybdenum, selenium and zinc. ${ }^{4}$

Zinc is important trace element which plays essential role in oxidative stress in the human body by working as antioxidant. Zinc is the part of copper zinc superoxide dismutase and many metallothioneins which are the important antioxidant system of human body. ${ }^{5}$

Previous literature revealed that DM was associated with low zinc level. Either DM occurred due to zinc deficiency due to more oxidative stress 
or DM caused zinc deficiency by poor absorption or due to overuse, the cause relationship not yet established $^{6}$ so this deficiency can be counter balance by zinc replacement as it revealed in previous studies to have health benefits in healthy individuals and also in diabetic patients as previous research demonstrated protective effect of zinc for diabetes. ${ }^{7}$

A meta-analysis and systematic review by Jayawardena et al demonstrated beneficial effect of zinc supplements on glycemic control. ${ }^{8}$

Another meta-analysis done by Capdor et al on zinc supplement in diabetic patients also revealed the zinc supplement reduced the fasting blood sugar and overall glycemic control improved by decreasing $\mathrm{HbA} 1 \mathrm{c} .^{9}$

Both ofthesemeta-analysisand systematic reviews demonstrated the benefit of zinc supplements in diabetic patients but they included small studies and the magnitude of decreasing fasting blood sugar was $0.5-1 \mathrm{mmol} / \mathrm{dl}$ and for $\mathrm{HbA} 1 \mathrm{c}$ was only $0.6 \%$ which is statistically significant but clinical implication is difficult. In addition to that some studies were single blind placebo controlled studies which may have some bias.

Lipid abnormalities are common and usually asymptomatic and not known to diabetic patients and their care giver until properly investigated. The impact of lipid abnormalities on macrovascular complication was studies and it was found that it increased the cardiovascular morbidity and mortality. ${ }^{10}$ The literature demonstrate that supplement of zinc not only improve the glycemic control but also had positive effect on lipid abnormalities. A study done by Afkhami-Ardekani revealed that zinc supplementation reduced total cholesterol and triglyceride level in diabetic patients. ${ }^{11}$

Another study also revealed the same results like reduction in total cholesterol, LDL cholesterol and triglycerides by zinc supplement. ${ }^{12}$

There are certain studies done previously and revealed the beneficial effects of zinc on glycemic control and lipid profile in diabetic patients as mentioned above, but still zinc diet or zinc supplement is not established in the management of type $2 \mathrm{DM}$ in guidelines may be due to small studies or single blind placebo controlled studies. Therefore we conducted a double blind placebo controlled trial in 350 diabetic patients to evaluate effect of zinc on glycemic control and lipid profile.

This study was done to investigate the benefit of zinc on glycemic control and lipid profile in type 2 diabetic patients.

Our objective of the study was to demonstrate effect of zinc supplement on blood glucose and lipid profile in type 2 diabetic patients.

We had hypotheses that zinc would have beneficial effect in type 2 diabetic patients in regards of glycemic control and would have beneficial effect on the lipid abnormalities.

\section{MATERIAL \& METHODS}

This double blind randomized controlled trial was done at Medical OPD at Combined Milatary Hospital $(\mathrm{CMH})$ Malir Cantt Karachi, over a period of six months from 1st December 2018 to 30th June, 2019. Three hundred and fifty type 2 diabetic patients, who fulfilled the inclusion criteria, were divided in to two groups, the first group received zinc sulphate (ZnSO4) $30 \mathrm{mg}$ once daily for 3 months and was given name of intervention group while other group was given starch tablet as placebo for 3 months and named as control group. The selections of patients were done on randomized basis. The randomization was done manually as to take every 2nd patient fulfilling the inclusion criteria for intervention and every 3rd patient fulfilling inclusion criteria for control group. Before starting the study all base line investigations such as $\mathrm{CBC}$, FBS, HBA1c, serum urea and creatinine, LFT, s Lipid profile and BMI was done. The zinc sulphate tablet (intervention) and starch tablet (placebo) were labeled as IN001 and IN002 respectively. The prescribers and patients were not aware that what tablet they are prescribing or receiving (double blind study). The full course of these medications was given at recruitment and possible side effects like nausea, 
vomiting or diarrhea were explained and in case of any side effect patients were asked to report Medical OPD personally or to call investigators (the mobile numbers of investigators provided to all patients). The starch tablets were manufactured locally and purchased from medicine market.

The sample size was calculated by the formula available on survey monkey website ${ }^{13}$, by putting population 100,000 , confidence interval $90 \%$ and margin of error 5\%. The total number was 269. Considering that $20 \%$ of the subject would have negative response by type 2 error so the sample size calculated as minimum number of 323 subjects with power of study $80 \%$.

All patients above age of 30 years or above with type 2 diabetes mellitus presented to Medicine OPD at Combined Military Hospital $(\mathrm{CMH})$ Malir Cantt Karachi were included in the study.

All Pregnant patients, Patients with heart failure, liver failure or renal failure, Patients taking diuretics and other drugs and already taking multivitamin or mineral supplements were excluded from study.

All patients, after informed consent and approval from ethical committee, went through history taking (demographic data collection), examination (specially neurological and fundus examination) and laboratory investigation like fasting blood sugar (FBS), Glycosylated hemoglobin (HbA1c), lipid profile, liver function test, urea and creatinine, ray chest, electrocardiography, FBS, HbA1c and lipid profile were done at baseline and repeated after 3 months.

$\mathrm{HbA} 1 \mathrm{c}$ was done on auto analyzer and reference range was $5.7 \%-6.4 \%$. FBS and the lipid profile was done on auto analyzer and reference range was $80 \mathrm{mg} / \mathrm{dl}-100 \mathrm{mg} / \mathrm{dl}$ and for total cholesterol, LDL,HDL and Triglycerides were < 200mg/ $\mathrm{dl}$, < 100mg/dl, > 40mg/dl and < 200mg/dl respectively.

All patients tolerated the $\mathrm{ZnSO} 4$ and placebo and did follow up. Those who did not come for follow up were contacted on their mobile phones and facilitated for follow up. The compliance of intake of $\mathrm{ZnSO} 4$ or placebo was $100 \%$. There was no reported side effect of nausea, vomiting, diarrhea or any other complaint.

All patients (350 patients) were analyzed using software SPSS version 22 (IBM). The chi square was applied for qualitative data and student $t$ test for unpaired samples was used to compare placebo group with $\mathrm{ZnSO} 4$ group. The $\mathrm{t}$ test for paired samples was used in both groups separately to compare baseline and 3 months results of FBS, HbA1c and lipid profile. The $p$ value $<0.05$ was considered significant.

\section{DEFINITION}

Type 2 diabetes mellitus

The diagnosis of type 2 DM was done according to American Diabetic Association criteria. ${ }^{14}$

Poor glycemic control

$\mathrm{HbA} 1 \mathrm{c}>7 \%$ was considered as poor glycemic control.

Good glycemic control

$\mathrm{HbA} 1 \mathrm{c}<7 \%$ was considered as good glycemic control.

\section{RESULTS}

Among three hundred and fifty $(n=350)$ patients, $50 \%(n=175)$ received zinc sulphate $30 \mathrm{mg}$ per day for 3 months, whereas $50 \%$ patients $(n=175)$ received placebo for 3 months. The mean age of all subjects was $51.80+10.281$ years and the mean age of zinc sulphate group was $51.21+10.115$ years, whereas the mean age of placebo group was $52.27+10.446$ years and there was no statistical difference between the two groups regarding age $(p=0.337)$. The male to female ratio was 1.08:1, in placebo group it was $1.3: 1$, but in ZnSO4 group it was $0.84: 1$, which revealed that more number of female patient received ZnSO4 but it was not statistically significant $(p=0.12)$. [Table-I]. The mean BMI was $31.74+5.806$. the mean BMI for ZnSO4 group was $30.14+5.273$ whereas it was $33.33+5.889$ for placebo group and increased BMI was significantly associated with placebo group $(p<0.001)$ means more 
obese subjects received placebo [Table-I\&II]. The mean FBS was $143.66+21.787 \mathrm{mg} / \mathrm{dl}$ in all subjects at baseline and mean FBS in $\mathrm{ZnSO} 4$ group was $141.05+21.155 \mathrm{mg} / \mathrm{dl}$, but it was $146.27+22.189 \mathrm{mg} / \mathrm{dl}$ in placebo group and there was statistical significant difference observed between the two groups regarding FBS $(p=0.25)$ so subjects with higher FBS received placebo. The overall mean $\mathrm{HbA1c}$ was $9.15 \%$, the mean $\mathrm{HbA} 1 \mathrm{c}$ in $\mathrm{ZnSO} 4$ group was $8.887 \%$ whereas it was $9.415 \%$ in placebo group so the subjects with higher hbA1c received placebo $(p<0.001)$. The overall mean cholesterol, triglycerides and LDL were $272.77+30.224,252.86+43.580$, and $172.10+29.284$ respectively. There was no statistical significant difference between ZnSO4 and placebo group regarding cholesterol, Triglyceride and LDL levels at baseline $(p=0.120$, 0.154 and 0.316 respectively Table-III.

The mean baseline FBS was $141.05+21.55$ in ZnSO4 group and it became $140.87+21.301$ after three months of $\mathrm{ZnSO} 4$ therapy, there was significant reduction in FBS after 3 months of ZnSO4 therapy $(p=0.032)$ [table-III]. The mean baseline FBS was $146.27+22.153$ in placebo group and it became $146.23+22.189$ after three months of placebo therapy, so, there was no significant reduction in FBS after 3 months therapy of placebo $(p=0.158)$ [Table-III].

The mean baseline HbA1c was $9.415+1.214$ in ZnSO4 group and it became 9.804+ 4.655 after three months of placebo therapy, there was significant reduction in $\mathrm{HbA} 1 \mathrm{c}$ after 3 months of ZnSO4 therapy $(p<0.001)$ [Table-III]. The mean baseline $\mathrm{HbA} 1 \mathrm{c}$ was $18.887+1.424$ in placebo group and it became $8.417+1.396$ after three months of placebo therapy, so, there was no significant reduction in $\mathrm{HbA} 1 \mathrm{c}$ after 3 months of therapy of placebo $(p=0.273)$ [Table-III]. There was significant reduction in cholesterol, triglycerides and LDL levels after 3 month therapy of ZnSO4 $(p<0.001)$ but there was no significant difference with placebo therapy [Table-III].

\begin{tabular}{|c|c|c|c|c|c|c|}
\hline Variables & Sub-variables & Zinc Sulphate Group & Placebo Group & Total & DF & P-Value \\
\hline \multirow[t]{2}{*}{ Age } & $<50$ & 124 & 114 & 238 & & \\
\hline & $>50$ & 51 & 61 & 112 & & \\
\hline Total & & 175 & 175 & 350 & 1 & 0.151 \\
\hline \multirow[t]{2}{*}{ Gender } & Male & 80 & 102 & 182 & & \\
\hline & Female & 95 & 73 & 168 & & \\
\hline Total & & 175 & 175 & 350 & 1 & 0.12 \\
\hline \multirow[t]{5}{*}{ BMI } & Normal & 27 & 13 & 40 & & \\
\hline & Overweight & 60 & 38 & 98 & & \\
\hline & Obesity I & 51 & 53 & 104 & & \\
\hline & Obesity II & 30 & 39 & 69 & & \\
\hline & Obesity III & 7 & 32 & 39 & & \\
\hline Total & & 175 & 175 & 350 & 4 & $<001$ \\
\hline
\end{tabular}




\begin{tabular}{|c|c|c|c|c|c|c|}
\hline & Intervention & $\mathbf{N}$ & Mean & $\begin{array}{c}\text { Std. } \\
\text { Deviation }\end{array}$ & $\begin{array}{l}\text { Std. Error } \\
\text { Mean }\end{array}$ & Sig. (2-tailed)* \\
\hline \multirow{2}{*}{ Age } & zinc sulphate group & 175 & 51.21 & 10.115 & .765 & \\
\hline & placebo group & 175 & 52.27 & 10.446 & .790 & .337 \\
\hline \multirow{2}{*}{ BMI } & zinc sulphate group & 175 & 30.14 & 5.273 & .399 & \\
\hline & placebo group & 175 & 33.33 & 5.889 & .445 & .000 \\
\hline FBS at baseline & zinc sulphate group & 175 & 141.05 & 21.155 & 1.599 & \\
\hline \multirow{2}{*}{ FBS after 3 months } & zinc sulphate group & 175 & 140.87 & 21.301 & 1.610 & \\
\hline & placebo group & 175 & 146.23 & 22.189 & 1.677 & .022 \\
\hline \multirow{2}{*}{ HbA1c at baseline } & zinc sulphate group & 175 & 8.887 & 1.4246 & .1077 & \\
\hline & placebo group & 175 & 9.415 & 1.2145 & .0918 & .000 \\
\hline HbA1c after 3 months & zinc sulphate group & 175 & 8.417 & 1.3967 & .1056 & \\
\hline \multirow{2}{*}{$\begin{array}{l}\text { Cholesterol after } 3 \\
\text { months }\end{array}$} & zinc sulphate group & 175 & 272.38 & 36.637 & 2.770 & \\
\hline & placebo group & 175 & 270.26 & 23.734 & 1.794 & .522 \\
\hline \multirow{2}{*}{ Triglyceride at baseline } & zinc sulphate group & 175 & 249.54 & 44.228 & 3.343 & \\
\hline & placebo group & 175 & 256.18 & 42.792 & 3.235 & .154 \\
\hline \multirow{2}{*}{$\begin{array}{l}\text { Triglycerides after } 3 \\
\text { months }\end{array}$} & zinc sulphate group & 175 & 245.38 & 44.501 & 3.364 & \\
\hline & placebo group & 175 & 256.14 & 42.870 & 3.241 & .022 \\
\hline \multirow{2}{*}{ LDL at baseline } & zinc sulphate group & 175 & 173.67 & 33.347 & 2.521 & \\
\hline & placebo group & 175 & 170.53 & 24.557 & 1.856 & .316 \\
\hline \multirow{2}{*}{ LDL after 3 months } & zinc sulphate group & 175 & 169.82 & 32.118 & 2.428 & \\
\hline & placebo group & 175 & 170.53 & 24.563 & 1.857 & .817 \\
\hline
\end{tabular}

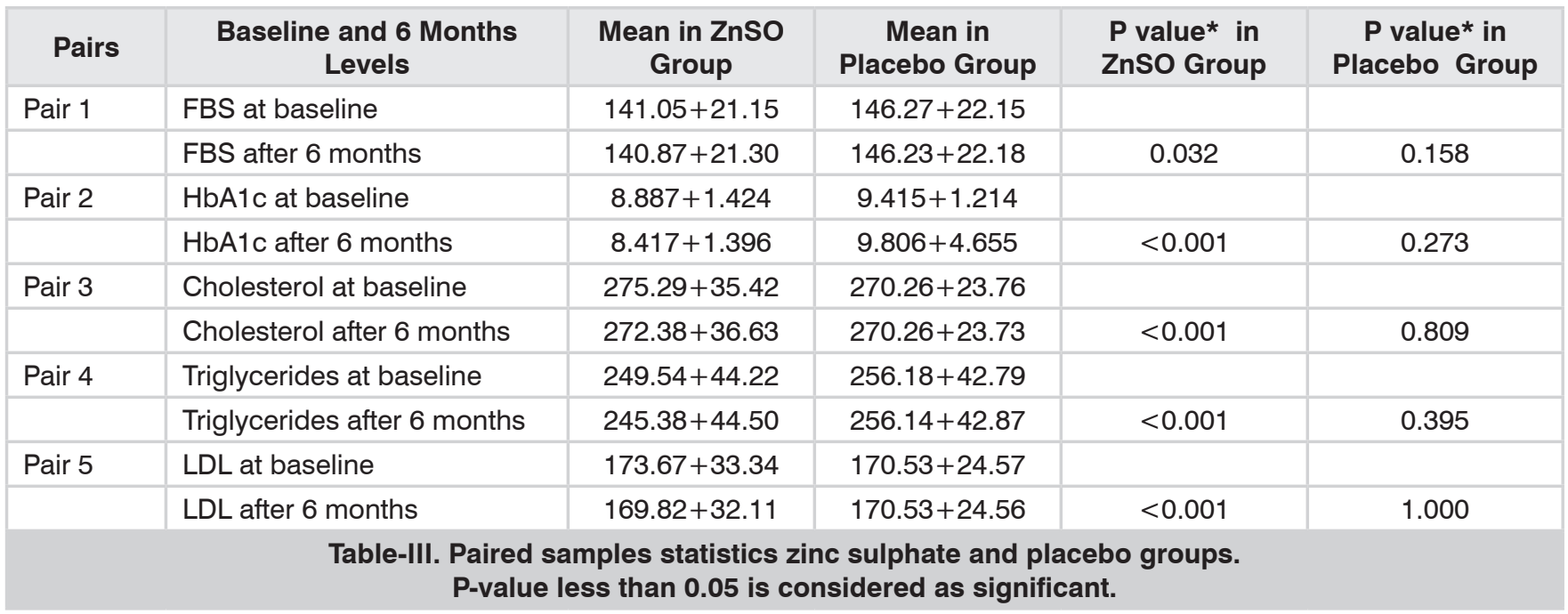

\section{DISCUSSION}

Our study revealed that there was significant reduction in FBS after 3 months supplementation of $\mathrm{ZnSO} 4 \quad(p=0.032)$ compared to placebo $(p=0.158)$ and there was significant reduction in HbA1c after 3 months supplementation of ZnSO4 $(p<0.001)$ compared to placebo $(p=0.273)$, so the study showed improvement in glycemic control with $\mathrm{ZnSO} 4$ supplements. This is consistent with the study from Iran, done by Afkhami-Ardekani et al. which revealed there was a significant reduction in $\mathrm{HbA} 1 \mathrm{C}$ level $(p=0.04) .{ }^{11}$ 
It is also similar to the study done by Al-Maroof, in which there was significant reduction in $\mathrm{HbA} 1 \mathrm{c}$ in the group which received supplement of $30 \mathrm{mg}$ ZnSO4 daily for 3 months. ${ }^{15}$ One study done on mice demonstrated that zinc supplement decreased fasting blood glucose compared to placebo group. ${ }^{16}$

One other study done in Bangladesh by Islam R.et al also demonstrated the significant reduction in fasting blood sugar with $\mathrm{ZnSO} 4$ supplement compared to placebo $(p<0.001) \cdot{ }^{17}$ Another study from Bangladesh revealed that zinc therapy achieved good glycemic control and improved peripheral neuropathy as assessed by nerve conduction velocity. ${ }^{18}$

On the contrast no beneficial effect of zinc supplement was observed in a study done in USA by Niewoehner et al. and another study done in Singapore by Seet RCS et al. ${ }^{19,20}$ But a study from Srillanka by Gunasekara et al. revealed that zinc supplementation improved glycemic control measured by $\mathrm{HbA} 1 \mathrm{C} \%$ and fasting and postprandial glucose. ${ }^{21}$ These results supported by Hussain et al. who demonstrated a $25 \%$ reduction in $\mathrm{FBS}$ and a $17 \%$ reduction in $\mathrm{HbA} 1 \mathrm{C} \%$ with 3 months supplementation with zinc and melatonin. ${ }^{22} \mathrm{~A}$ study from India also demonstrated that $\mathrm{ZnSO} 4$ supplement for only 6 weeks reduced significantly fasting and postprandial blood glucose level and there was improvement in diabetic neuropathy. ${ }^{23}$

The effect of zinc on glycemic control was supported by literature that Zinc has important role in decreasing peripheral insulin resistance. It increases insulin stimulated glucose transport. ${ }^{24}$

Our study revealed that there was significant reduction in cholesterol, triglyceride and LDL levels after three month supplement of $\mathrm{ZnSO} 4$ compared to baseline and placebo group where there was no significant change in levels of cholesterol, triglycerides and LDL.

These findings were consistent with the study by Partida-Hernández et al. which demonstrated that 100mg ZnSO4 for 3 months significantly reduced cholesterol and triglycerides and increased level of HDL compared to placebo. ${ }^{25}$ In our study the dose of $\mathrm{ZnSO} 4$ was $30 \mathrm{mg}$ per day for 3 months and we could not analyzed the HDL data as it was not reported in most of the patients. A study from Iraq by Kadhim HM revealed that there was reduction of total cholesterol, triglycerides and LDL level after 90 days supplement of $50 \mathrm{mg}$ ZnSO4 with $10 \mathrm{mg}$ melatonin. ${ }^{12}$

A study from Srilanka mentioned above also demonstrated that in addition to good glycemic control the supplement of $\mathrm{ZnSO} 4$ decreased total cholesterol and total cholesterol HDL ratio. ${ }^{21}$ Similarly A study from Iran by Afkhami-Ardekani revealed that there was Reduction in TG, TC, and LDL with ZnSO4 supplement compared to placebo. ${ }^{11}$

These findings are in contrast to results from a previous meta-analysis of controlled trials involving healthy subjects, where no beneficial effects of Zinc supplementation were observed on plasma total cholesterol, LDL-C, HDL-c or TAG concentrations ${ }^{26}$ The same meta-analysis showed that Zinc supplementation in healthy individuals was associated with a significant reduction of plasma HDL-c concentrations (7\% decreases from baseline). ${ }^{26}$ In contrast to our findings, the above meta-analysis suggests that Zinc supplementation in healthy individuals may not have beneficial health effects. This relationship between Zinc supplementation in healthy individuals and HDL-c levels appears to an extent to depend upon Zinc dosage and duration of supplementation. ${ }^{26}$ Serum HDL-c levels appear to decrease at Zinc doses of over $50 \mathrm{mg} / \mathrm{day}$ given for at least three months. ${ }^{26}$ In addition to the lowering of HDL-C by zinc supplementation in healthy individuals, several adverse effects are also reported in the literature. Studies have shown that sustained hyperzincaemia may predispose individuals to thrombogenesis. ${ }^{27}$ However, studies have shown that physiological doses of Zinc supplementation (20mg/day) for short durations (2 months) produced favorable effects on nutritional and immune status in marginally Zinc deficient elderly individuals, while there were no significant changes observed in the plasma 
HDL-c levels. ${ }^{28}$ Hence, from these findings we can conclude that supplementing Zinc may favorably alter lipid metabolism in patients with diabetes, but not in healthy individuals. Most of the studies included in that meta-analysis were conducted in low-middle income developing countries where marginal Zinc deficiency might be highly prevalent, amongst patients with diabetes. Thus, it appears that the beneficial effects of Zinc supplementation on metabolic parameters can be seen mainly in individuals with Zinc deficiency or diseases causing Zinc deficiency such as diabetes. This also plays a major role in its pathogenesis. Oxidative stress and oxidative damage to tissues is known to occur in diabetes and may be associated with its' complications. Farvid and coworkers reported beneficial effects on diabetes neuropathy and nephropathy by Zinc supplementation. ${ }^{29,30}$

Thus it is possible to hypothesis that reduction in diabetes complication may be due to reduction of oxidative damage from Zinc supplementation.

The complication of diabetes occur between 5 and 10 years after being diagnosed and are closely related with their metabolic disorder and degree of severity, this depends on its duration. CVD prevention is known to be important in the management of diabetes to reduce morbidity and mortality. The supplement of zinc decreased glycemic load, reduced oxidative stress, and reduced LDL, total cholesterol, and triglycerides, hence reduced the risk of complications especially cardiovascular complications.

The reduction of $\mathrm{HbA} 1 \mathrm{c}$ after 3 month therapy of ZnSO4 was 0.47 , which is significant reduction $p<0.001$. This cannot be comparable to any oral hypoglycemic drugs because no head to head trials done but this significant reduction in $\mathrm{HbA1c}$ may prevent or delay the complications of diabetes. We did not study the effect of ZnSO4 on complications of diabetes but it was demonstrated previous studies. Many studies done to observe the role of zinc supplement to retard the progression of complications of DM. It was observed that zinc supplement reduced the severity of symptomatic neuropathy in patients with type $2 \mathrm{DM}$. it was also observed that zinc supplement Lowered urinary albumin excretion $^{30,31}$ Zinc supplement also retarded the diabetic retinopathy progression. ${ }^{31}$

There are some limitations of the study, at first; we could not able to do zinc level in the patients prior to start the study. So we could not say that all patients were zinc deficient, although it was demonstrated in previous study that diabetes is associated with low zinc level. The zinc test has high cost locally and it is not available in government hospitals like our hospital. On other hand the supplement of ZnSO4 showed improvement in glycemic control and lipid level so, this study may give the idea to start zinc supplement without doing the test or increasing the cost which is usually not bearable by common people of developing countries like Pakistan. Second limitation is that we did not get complete data of HDL so it was not analyzed in final analysis. Therefore we could not comment on improvement of lipid profile we may infer here that total cholesterol, triglycerides and LDL levels decrease with supplement of zinc but we don't know what happens to HDL, although the previous studies suggest that there is increase in HDL level with zinc supplement. Third, the data revealed that patients with higher fasting blood sugar and higher $\mathrm{HbA} 1 \mathrm{c}$ received placebo. The study was randomized and it happened by chance only but by these results one may infer that zinc supplement is only effective in mild to moderate hyperglycemia but severe hyperglycemia may not be affected by zinc supplements. It May be true because toxic effect of severe hyperglycemia impairs the function of pancreas. Although there are some limitations but our study is double blind randomized controlled trials, it has high power, and it is one of the few studies done in poor resource countries and may be the first study from Pakistan. Furthermore, it may strengthen the hypotheses of zinc replacement in diabetic patients.

\section{CONCLUSION}

We conclude here that Zinc supplement for short duration like 3 months has significant benefit in diabetic patients. It improves the glycemic control and reduces total cholesterol, triglycerides 
and LDL levels. As we know from literature that high zinc level is not safe. Therefore, we cannot recommend blind supplements of zinc without knowing zinc status in the body. We recommend further well designed larger studies with measurement of zinc level before and after zinc supplements, which may show relationship of zinc supplement to zinc level and glycemic control.

\section{Contributions of Authors}

The first author brought the idea of study and study design was agreed by 2nd, 3rd, 4rth, 5th and 6 th authours. The data collection was done by all authors. The The first author wrote introduction \& data analysis .The abstract and results were written by 1 st and 2 nd author. The discussion and conclusion were written by 1st and 3rd author .The overall correction in the whole article and finally format the text done and send to journal by 4rth author, statical analysis was done by 5th author and six author written the introduction.

\section{Copyright@ 25 Jan, 2020.}

\section{REFERENCES}

1. Wahabi, H.A., Alzeidan, R.A., Bawazeer, G.A., Alansari, L.A. and Esmaeil, S.A. Preconception care for diabetic women for improving maternal and fetal outcomes: A systematic review and seta-analysis. BMC Pregnancy Childbirth 2010, 10: 63. doi:10.1186/1471-2393-10-63).

2. World Health Organization - Diabetes country profiles, 2016. http://www.who.int/diabetes/countryprofiles/pak_en.pdf.

3. Davidson MB, Schriger DL (2010.) Effect of age and race/ethnicity on HbA1c levels in people without known diabetes mellitus: implications for the diagnosis of diabetes. Diabetes Res Clin Pract. 2010 Mar; 87(3):415-21. doi: 10.1016/j.diabres.2009.12.013. Epub 2010 Jan 12

4. Nourmohammadi I, Shalmani IK, Shaabani M, Gohari L. Zinc, copper, chromium, manganese and magnesium levels in serum and hair of insulin-dependent diabetics. Arch Iranian Med 2000; 2:88-100.

5. King JC, Shames DM, Woodhouse LR. Zinc homeostasis in humans. J Nutr. 2000 May; 130(5S Suppl):1360S-1366S.
6. Arreola F, Paniagua R, Díaz-Bensussen S, Urquieta B, López-Montaño E, Partida- Hernández G, et al. Bone mineral content, 25-hydroxycalciferol and zinc serum levels in insulin dependent (type-1) diabetic patients. Arch Invest Med (Mex) 1990; 21:195-9.

7. Vashum KP, McEvoy M, Shi Z, Milton AH, Islam MR, Sibbritt $D$, et al. Is dietary zinc protective for type 2 diabetes? Results from the Australian longitudinal study on women's health. BMC Endocrine Disorders; October, 2013; (13):40 https://doi.org/10.1186/14726823-13-4.

8. Jayawardena R, Ranasinghe P, Galappatthy P, Malkanthi $R$, Constantine G, Katulanda P. Effects of zinc supplementation on diabetes mellitus: A systematic review and meta-analysis. Diabetol Metab Syndr. 2012 Apr 19; 4(1):13. doi: 10.1186/1758-5996-4-1.

9. Capdor J, Foster M, Petocz P, Samman S. Zinc and glycemic control: A meta-analysis of randomised placebo controlled supplementation trials in humans. J Trace Elem Med Biol. 2013 Apr; 27(2):13742. doi: 10.1016/j.jtemb.2012.08.001. Epub 2012 Nov 6.

10. Gordon L, Dalip Ragoobirsingh D, Morrison S. E. YA et al. Lipid Profile of Type 2 Diabetic and Hypertensive Patients in the Jamaican Population. J Lab Physicians. 2010 Jan-Jun; 2(1): 25-30. doi: 10.4103/09742727.66709.PMCID: PMC3147082.

11. Afkhami-Ardekani $M$, Karimi M, Mohammadi SM, Nourani F: Effect of zinc sulfate supplementation on lipid and glucose in type 2 diabetic patients. Pak $\mathrm{J}$ Nutr 2008, 7 (4): 550-553.

12. Kadhim HM, Ismail SH, Hussein KI, Bakir IH, Sahib AS, Khalaf BH, Hussain SA: Effects of melatonin and zinc on lipid profile and renal function in type 2 diabetic patients poorly controlled with metformin. J Pineal Res. 2006 Sep; 41(2):189-93.

13. Survey Monkey (https://www.surveymonkey.com/mp/ sample-size-calculator/.

14. Diabetes management guidelines american diabetes association (ADA) 2016 guidelines. http://www.ndei. org/ADA-diabetes-management-guidelines-diagnosisA1C-testing.aspx.html.

15. Al-Maroof RA, Al-Sharbatti SS. Serum zinc levels in diabetic patients and effect of zinc supplementation on glycemic control of type 2 diabetics. Saudi Med J. 2006 Mar; $27(3): 344-350$.

16. Simon SF, Taylor CG: Dietary zinc supplementation attenuates hyperglycemia in $\mathbf{d b} / \mathrm{db}$ mice. Exp Biol Med (Maywood). 2001 Jan; 226(1):43-51. 
17. Islam $R$ a,e,i, Attia $J$ a, Ali $L$ et al. Zinc supplementation for improving glucose handling in pre-diabetes: A double blind randomized placebo controlled pilot study. Diabetes Res Clin Pract. 2016 May; 115:39-46. doi: 10.1016/j.diabres.2016.03.010. Epub 2016 Mar 19.

18. Hayee MA, Mohammad QD, Haque A: Diabetic neuropathy and zinc therapy. Bangladesh Med Res Counc Bull. 2005 Aug; 31(2):62-67.

19. Niewoehner CB, Allen Jl, Boosalis M: Role of zinc supplementation in type II diabetes mellitus. Am J Med. 1986 Jul; 81(1):63-8.

20. Seet RCS, Lee CYJ, Lim ECH, Quek AML, Huang $\mathrm{H}$, Huang $\mathrm{SH}$, Looi WF, Long LH, Halliwell B: Oral zinc supplementation does not improve oxidative stress or vascular function in patients with type 2 diabetes with normal zinc levels. Atherosclerosis, 2011, Nov; 219(1):231-9 .doi:10.1016/j. atherosclerosis.2011.07.097. Epub $2011 \mathrm{Jul} 26$.

21. Gunasekara $P$, Hettiarachchi M, Liyanage C, Lekamwasam S: Effects of zinc and multimineral vitamin supplementation on glycemic and lipid control in adult diabetes. Diabetes, Metabolic Syndrome and Obesity: Targets and Therapy 2011, 4:53-60. doi: 10.2147/DMSO.S16691

22. Hussain SA, Khadim $\mathrm{HM}$, Khalaf $\mathrm{BH}$, et al. Effect of melatonin and zinc on glycaemic control in type 2 diabetic patients poorly controlled with metformin. Saudi Med J. 2006 Oct; 27(10):1483-8.

23. Gupta R, Garg VK, Mathur DK, Goyal RK: Oral zinc therapy in diabetic neuropathy. J Assoc Physicians India. 1998 Nov; 46(11):939-42.

24. Tang X, Shay NF: Zinc has an insulin-like effect on glucose transport mediated by phosphoinositol-3kinase and Akt in 3 T3-L1 fibroblasts and adipocytes. J Nutr. 2001 May; 131(5):1414-20.
25. Partida-Hernández G, Arreola F, Fenton B, Cabeza M, Román-Ramos R, Revilla-Monsalve MC: Effect of zinc replacement on lipids and lipoproteins in type 2-diabetic patients. Biomed Pharmacother 2006, 60:161-168.

26. Foster M, Petocz P, Samman S: Effects of zinc on plasma lipoprotein cholesterol concentrations in humans: A meta-analysis of randomized controlled trials. Atherosclerosis. 2010, Jun; 210(2):344-52. doi:10.1016/j.atherosclerosis.2009.11.038. Epub 2009 Nov 29.

27. Hughes S, Samman S: The effect of zinc supplementation in humans on plasma lipids, antioxidant status and thrombogenesis. J Am Coll Nutr. 2006 Aug; 25(4):285-91.

28. Boukaiba N, Flament C, Acher S, Chappuis P, Piau A, Fusselier M, Dardenne M, Lemonnier D: A physiological amount of zinc supplementation: Effects on nutritional, lipid, and thymic status in an elderly population. Am J Clin Nutr. 1993 Apr; 57(4):566-72.

29. Farvid MS, Homayouni F, Amiri Z, Adelmanesh F: Improving neuropathy scores in type $\mathbf{2}$ diabetic patients using micronutrients supplementation. Diabetes Res Clin Pract. 2011 Jul; 93(1):86-94. doi: 10.1016/j.diabres. 2011.03.016. Epub 2011 Apr 14.

30. Farvid MS, Jalali M, Siassi F, Hosseini M: Comparison of the effects of vitamins and/or mineral supplementation on glomerular and tubular dysfunction in type 2 diabetes. Diabetes Care. 2005 Oct; 28(10):2458-64.

31. Garcia-Medina JJ, Pinazo-Duran MD, Garcia-Medina M, Zanon-Moreno V, Pons-Vazquez S: A 5-year followup of antioxidant supplementation in type 2 diabetic retinopathy. Eur J Ophthalmol 2011, 21:637-643.

\begin{tabular}{|c|c|c|c|}
\hline \multicolumn{4}{|c|}{ AUTHORSHIP AND CONTRIBUTION DECLARATION } \\
\hline Sr. \# & Author(s) Full Name & Contribution to the paper & Author(s) Signature \\
\hline 2 & $\begin{array}{l}\text { M. Farooq } \\
\text { Arshad Ali }\end{array}$ & $\begin{array}{l}\text { Brought the idea of study, Data collection was done, } \\
\text { Wrote introduction, Analysis was done, Resutls were } \\
\text { written, Discussion and conclusion were written, The } \\
\text { abstract was written. } \\
\text { Study design was agreed, Data collection was done. }\end{array}$ & \\
\hline 3 & Nayyer UI Islam & Study design was agreed, Data collection was done. & \\
\hline 4 & Furquana Niaz & $\begin{array}{l}\text { Data collection was done, The overall correction in the } \\
\text { article and final format of text done and send to the } \\
\text { journal. }\end{array}$ & \\
\hline 5 & Yousuf UI Islam & $\begin{array}{l}\text { Data collection was done, Data analysis (Static) was } \\
\text { done. }\end{array}$ & \\
\hline 6 & Urooj Tabassum & Data collection was done, Introduction were written. & \\
\hline
\end{tabular}

